DOI

http://dx.doi.org/10.1590/2236-463320150913

Political Debate and Economic

Thought in the Brazilian Empire: Power

Centralization and Issuing Monopoly in the second Bank of Brazil (1852-1853)

\section{0 debate político e o pensamento econômico no Império brasileiro: centralização de poder e monopólio de emissão no segundo Banco do Brasil (1852-1853)}

Thiago Fontelas Rosado Gambi

Professor no Instituto de Ciências Sociais Aplicadas da Universidade Federal de Alfenas (ICSA/UNIFAL Varginha-MG/Brasil)

e-mail: thiago.gambi@uol.com.br

\section{Resumo}

A criação do segundo Banco do Brasil por Joaquim José Rodrigues Torres, em 1853, passa pelo debate político entre os chamados papelistas e metalistas. 0 objetivo do artigo é mostrar como o debate políticoeconômico entre os chamados papelistas e metalistas guiou a instituição do monopólio emissor no Império brasileiro. Para tanto, caracteriza primeiro os princípios econômicos em que se baseavam a banking school e a currency school inglesas. Na segunda parte, aborda a adaptação daqueles princípios à realidade nacional. Finalmente, mostra como os principais contendores daquele debate no parlamento trataram especificamente da questão emissora no Império, mesclando monopólio de emissão e centralização do poder político.

\begin{abstract}
The creation of the second Bank of Brazil by Joaquim José Rodrigues Torres, in 1853, pass through the political debate between the so-called papelistas and metalistas. The aim of this paper is to show the influence of this debate on the institution of issuing monopoly in the Brazilian Empire. The paper first characterizes currency and banking school economic principles. Second, the article addresses the adaptation of those principles to the national reality. Finally, shows how the main contenders in that parliament debate dealt specifically with the creation of an issuing bank in the Empire.
\end{abstract}

Palavras-chave

Banco do Brasil, metalistas, papelistas

Keywords

Bank of Brazil, metalists, papelists 
Neste trabalho, optamos por chamar essa instituição de segundo Banco do Brasil, porque a ênfase de nossa análise está na relação entre 0 banco e o Estado imperial e, portanto, os critérios de maior peso em nossa escolha são o fato de sua criação ter sido motivada pela iniciativa pública e de ter ela entrado efetivamente em operação. Não faz sentido considerarmos o banco estabelecido pela lei de 1833, uma vez que não chegou a operar e, portanto, a se relacionar efetivamente com o Estado. Tampouco faz sentido considerarmos no cômputo o banco de 1851, uma vez que foi criado pela iniciativa privada e não possuía vínculos formais com Estado.

\section{Introdução}

A criação do segundo Banco do Brasil' por Joaquim José Rodrigues Torres, em 1853, passa pelo debate político entre os chamados papelistas e metalistas. 0 objetivo do artigo é mostrar como esse debate guiou a política econômica imperial de meados do século XIX, com a instituição do monopólio de emissão no Império por meio de um banco privado, mas tutelado pelo governo. Com o pano de fundo da centralização política, os chamados metalistas tentavam justificar economicamente a implementação do monopólio emissor. Contudo, ainda que essa política econômica aparentemente fosse usada para legitimar o objetivo final do Partido Conservador de centralização do poder político na Corte, sendo coerente com tal propósito, não se pode negar a convicção de Rodrigues Torres nas idéias metalistas, adaptadas às condições econômicas do país, e na crença de que o banco por ele criado poderia dar ao Império uma moeda forte.

Para mostrar, então, como a discussão sobre o monopólio de emissão aparecia no debate econômico, o artigo caracteriza primeiro os princípios econômicos em que se baseavam a banking school e a currency school inglesas, influenciadoras dos chamados papelistas e metalistas brasileiros. Na segunda parte, trata da "tropicalização" desse debate, com a adaptação daqueles princípios à realidade nacional. Finalmente, na terceira parte, mostra como os principais contendores desse debate no parlamento, Bernardo de Souza Franco e Joaquim José Rodrigues Torres, trataram especificamente da questão emissora no Império, mesclando monopólio de emissão e centralização do poder político.

0 debate econômico de meados do século XIX enfatizava a busca por uma moeda forte e a manutenção de seu valor. Ao mesmo tempo, não podia negligenciar a demanda por crédito, importante para o funcionamento da economia imperial. A moeda e o crédito sempre foram uma preocupação e um problema para diversos governos desde a criação do primeiro Banco do Brasil em 1808. 0 padrão-ouro será uma miragem por praticamente todo o periodo imperial. A demanda do comércio por moeda e crédito, ou as demandas do próprio Estado, e a política de valorização do meio circulante levada a cabo no Segundo Império entabulavam um conflito que evidenciava a fragilidade da estrutura econômica brasileira e a impossibilidade de se concretizar tal padrão monetário. Em outras palavras, expressava-se o conflito entre a desordem do crédito e a ordem da moeda. Não haveria metal suficiente que pudesse atender ao mesmo tempo a necessidade geral de recursos e a política de valorização do meio circulante. No marco dessa contradição, o governo equilibrava-se entre a desordem e a ordem, mesmo porque não havia alternativa. A concretização do padrão -ouro permanecia como miragem.

A reforma monetária de 1846 é uma amostra dessa permanência, ainda que significasse uma "desvalorização para valorizar" a moeda imperial. Mas tratava-se de nova quimera. Ao não adotar de vez a moeda fiduciária, optando por definir novo padrão para a moeda brasileira, o governo revelava sua fixação ao padrão-ouro. As implicações desse regime são conhecidas. Além do atrelamento da moeda a certo peso de ouro, 0 dinheiro metálico devia ter liberdade para circular internamente e as notas bancárias que estivessem em circulação deveriam ser plenamente conversíveis em ouro. Aliás, qualquer moeda em circulação devia estar atrelada ao ouro. Por fim, para garantir a estabilidade do valor da moeda, não deveria existir qualquer impedimento à entrada ou saída de metal do país. 
2

VIEIRA, Dorival Teixeira. Evolução do sistema monetário brasileiro. São Paulo: IPE/USP, 1981.

3 FAORO, Raymundo. Os donos do poder. São Paulo: Publifolha, 2000. v.2, p.6.

Para os periodos em que se verificou a paridade de 27 d., cf. VILLELA, André Arruda. The political economy of money and banking in Imperial Brazil 1850-1870. 1999. 332f. Tese (Doutorado em História econômica). The London School of Economics and Political Science, Londres, 1999. p.228.

5

Para citar apenas alguns autores, SAES, Flávio Azevedo Marques de. Crédito e bancos no desenvolvimento da economia paulista 18501930. São Paulo: IPE/USP, 1986; ANDRADE, Ana Maria Ribeiro de. 1864: a controvérsia entre papelistas e metalistas. 1987. 197f. Dissertação (Mestrado em História). Instituto de Filosofia e Ciências Sociais. Universidade Federal do Rio de Janeiro, Rio de Janeiro, 1987; GREMAUD, Amaury Patrick. Das controvérsias teóricas à política econômica: pensamento econômico e economia brasileira no Segundo Império e na primeira república (1840-1930). 1997. 165f. Tese (Doutorado em Economia). Faculdade de Economia, Administração e Contabilidade. Universidade de São Paulo, São Paulo, 1997; TEIXEIRA, Arilda Magna Campanharo. Determinantes e armadilhas da política monetária brasileira no II Império. 1991. 120f. Dissertação (Mestrado em Economia). Faculdade de Economia. Universidade Federal Fluminense, Niterói, 1991; VILLELA, André Arruda. Op. Cit.; FONSECA, Pedro Cezar Dutra. A controvérsia entre papelismo e metalismo e a gênese do desenvolvimentismo no Brasil. In: ENCONTRO NACIONAL DE ECONOMIA DA ANPEC, 36., 2008, Salvador. Anais do XXXVI Encontro Nacional da ANPEC. CD-ROM, 2008; SÁEZ, Hernán Enrique Lara. Nas asas de Dédalo: um estudo sobre o meio circulante no Brasil entre os anos de 1840 a 1853. 2008. 224f. Dissertação (Mestrado em História Econômica). Faculdade de Filosofia, Letras e Ciências Humanas, Universidade de São Paulo, 2008
Funcionando nesse regime e apesar da quebra do padrão, o mil-réis valorizou-se, isto é, embora a nova paridade representasse uma desvalorização em relação à paridade anterior, ao mesmo tempo, significava uma valorização em relação à taxa de câmbio de mercado, graças também ao aumento da oferta de ouro. ${ }^{2} \mathrm{~A}$ miragem do padrão-ouro parecia querer se concretizar. Um país civilizado e próspero exigia uma moeda forte, mas miragens são miragens. A paridade de $27 d$. estabelecida na reforma de 1846 só se verificou em breves períodos entre 1854 e 1864, depois da criação do segundo Banco do Brasil, e, mesmo assim, o meio circulante não estava totalmente lastreado em metal. Como observa Faoro ${ }^{3}$, o padrão -ouro no Brasil "nunca teve acolhida nos fatos, mas apenas nas palavras e nos desejos dos estadistas". 4 A manutenção da paridade de abril de 1854 a novembro de 1857 e o retorno a ela, de outubro de 1862 a setembro de 1864, reforçam a tese de que o segundo Banco do Brasil fora concebido e criado para assegurar primordialmente a estabilidade do valor da moeda e do câmbio. 0 padrão-ouro, ainda que como miragem, era uma virtude aos olhos de parcela importante dos conservadores, enquanto a moeda fiduciária era um vício.

Nesse mesmo período, meados do XIX, a criação de um banco nacional que pudesse resolver os problemas da moeda e do crédito no Império aparecia nas discussões que se travavam na Assembleia Geral Legislativa. A controvérsia entre papelistas e metalistas já foi bem estudada pela historiografia brasileira. ${ }^{5}$ Por isso, não faz sentido recuperar com profundidade todo o debate sobre as teorias monetárias em voga no exterior e a realidade econômica brasileira. Cabe, no entanto, situar no debate estrangeiro e nacional a discussão especifica sobre a pertinência de se criar um banco privado com monopólio emissor e atrelado ao Estado. Alguns dos pressupostos teóricos que estariam por trás da criação do segundo Banco do Brasil surgiram exatamente desse debate travado entre parlamentares nas décadas de 1840 e 1850, já no contexto da forte influência política do núcleo do Partido Conservador, os chamados saquaremas.

\section{Banking School e Currency School}

A controvérsia entre papelistas e metalistas no Brasil remete ao famoso debate entre os partidários da escola bancária e os da escola monetária na Inglaterra do século XIX. Contudo, não se tratava de mera transposição do debate inglês. As teorias econômicas defendidas por uma e outra escola eram conhecidas pelos parlamentares brasileiros e muitas vezes eram recebidas criticamente por aqui. Em que pese a prevalência das teorias monetárias concebidas na Europa, sobretudo a do padrão-ouro, sabia-se perfeitamente que adaptações teriam que ser feitas a essas teorias para que conseguissem dar conta da realidade econômica brasileira. Uma coisa era discutir a centralidade ou pluralidade da emissão numa economia que se industrializava, outra coisa era discutir o mesmo tema numa economia essencialmente agrária. Uma coisa era debater a conversibilidade ou inconversibilidade da emissão numa economia industrial e assalariada, outra coisa era debater o mesmo assunto numa economia essencialmente mercantil e escravista. E era justamente isso que se fazia.

0 referencial teórico dos debates entre papelistas e metalistas ocorridos no Brasil apontava para as idéias defendidas na Inglaterra pelas escolas bancária e monetária. 0 chamado princípio bancário dava o norte da escola bancária (podemos citar como representantes dessa escola Henry Thornton, 
6

Villela, baseado em White, adverte que o custo dos bancos emissores não era tão baixo como se imaginava à época. Cf. VILLELA, André Arruda. Op. Cit., p.211; WHITE, Lawrence. Free Banking in Britain: theory, experience and debate, 1800-45. Cambridge: Cambridge University Press, 1984.

7

KINDLEBERGER, Charles Poor. Keynesianism vs. Monetarism and Other Essays in Financial History. Londres: Taylor and Francis, 2006.
Thomas Tooke e John Fullarton). Tal princípio sustentava que notas bancárias só eram emitidas para efetivar operações de crédito que tinham como contrapartida transações comerciais já realizadas. Ora, se a emissão bancária tinha contrapartida real, ela não podia provocar inflação. Seu aumento nada mais era do que reflexo do aumento das transações comerciais. Este, sim, podia ou não provocar inflação. Portanto, segundo esse princípio, 0 sentido da causalidade vai da transação comercial (preço) para a emissão (oferta monetária) e não o contrário. Transações comerciais e emissão de notas bancárias funcionavam como duas faces de uma mesma moeda.

Enquanto a profusão de moeda metálica e a emissão de papel-moeda poderiam gerar inflação, a emissão de notas bancárias não correria o risco de produzir tal resultado, uma vez que apenas acompanhava o ritmo das transações comerciais já realizadas. 0 aumento da emissão de notas bancárias seria apenas indicador de um aumento das transações ou dos preços. Por isso, a escola bancária sustentava que, na questão monetária, as notas bancárias deviam ser diferenciadas da moeda metálica e do papel-moeda corrente.

Sua antípoda era a escola monetária (cujos representantes eram David Ricardo, Robert Peel e John McCulloch), guiada pelo chamado princípio monetário. Tal princípio, ligado à teoria quantitativa da moeda, sustentava que o aumento da oferta de moeda, notas bancárias inclusive, gerava inflação. Do mesmo modo, se a oferta de moeda se reduzisse, a inflação também cederia. Portanto, segundo esse princípio, o sentido da causalidade vai da oferta monetária para o preço e não o contrário. Nesse caso, as duas faces da moeda eram oferta monetária e preço. Já que qualquer aumento da oferta monetária poderia gerar inflação, não havia motivo para distinguir notas bancárias de outros tipos de moeda.

0 critério utilizado acima para apresentar sucintamente os princípios defendidos pelas duas escolas não poderia deixar de ser a inflação, uma vez que no cerne do debate monetário e creditício estava a questão da manutenção do valor do meio circulante. Isso afetava ao mesmo tempo a disponibilidade de moeda para a realização das transações, tema caro à escola bancária, e a variação da taxa de câmbio, tema caro à escola monetária.

Daí a conversibilidade das notas bancárias como bandeira comum defendida pelas duas escolas. Contudo, os princípios defendidos por elas acabavam desembocando em dois grandes pontos de conflito em torno de questões relacionadas ao direito de emissão e ao tipo de conversibilidade do meio circulante. Quanto ao direito de emissão, discutia-se a unidade ou pluralidade emissora como alternativas e, também, dado o caráter público e privado das emissões, se a instituição ou as instituições emissoras deveriam ser públicas ou privadas. A título de esclarecimento, o caráter público das emissões se revela nas conseqüências do aumento da oferta monetária para a economia como um todo. Tais conseqüências justificariam a intervenção do Estado nessa questão. Seu caráter privado surge da possibilidade de um banco emissor realizar lucros, com baixo custo, ${ }^{6}$ por meio do empréstimo das notas emitidas. Já o que se discutia em relação à conversibilidade dizia respeito ao tipo de reserva que serviria de lastro para as emissões, isto é, se elas deveriam ser lastreadas exclusivamente em ouro ou se também poderiam entrar como lastro notas do tesouro e ações de companhias abertas.

Trazendo esse debate para uma época mais recente, Kindleberger ${ }^{7}$ compara, de um lado, a escola monetária à teoria monetarista e, de outro, a escola bancária à teoria keynesiana, mostrando que a controvérsia 
Até o restabelecimento da conversibilidade em ouro das notas do Banco da Inglaterra, em 1819, os partidários do princípio monetário eram chamados de bullionistas e os partidários do princípio bancário de anti-bullionistas, numa referência ao Bullion Committe, formado em 1810

9

GILBART, James William. Tractado practico dos bancos. Rio de Janeiro: B. L. Garnier, 1859; SCHULZ, John. A crise financeira da abolição. São Paulo: Edusp/Instituto Fernand Braudel, 1996; GREMAUD, Amaury Patrick. Op. Cit.; VILLELA, André Arruda. Op. Cit.

10

SAES, Flávio Azevedo Marques de. 0p. Cit., p.28. Cf. também GREMAUD, Amaury Patrick. Op. Cit.; HUGON, Paul. A economia politica no Brasil. In: AZEVEDO, Fernando de. As ciências no Brasil. São Paulo: Melhoramentos, 1955.

11

SÁEZ, Hernán Enrique Lara. Op. Cit. permanece ao longo do tempo. Mas essa controvérsia monetária nasceu mesmo no final do século XVIII e girava em torno do valor da moeda e da atuação do Banco da Inglaterra. Interessante notar a semelhança com a discussão que se fazia no Brasil em relação ao valor da moeda e à atuação do Banco do Brasil. No início do século XIX, por exemplo, apresentava-se na Inglaterra a discussão sobre as causas da desvalorização da libra. A comissão formada pelo parlamento para investigar a questão apontou 0 excesso de emissão de notas por parte do Banco da Inglaterra como causa principal da desvalorização da moeda inglesa, diagnóstico claro de partidários do princípio monetário. ${ }^{8}$ Colocava-se em questão a administração permissiva do banco de emissão e seu efeito deletério sobre o valor da moeda. Foi o que aconteceu no Brasil um pouco mais tarde em relação ao mil-réis e ao primeiro Banco do Brasil. Mais radical, a solução brasileira foi a liquidação de seu banco emissor. Na Inglaterra, os debates entre as duas escolas se intensificaram, mas as posições da escola monetária acabavam prevalecendo, casos da regra Palmer, de 1827, e da lei de Peel, de 1844. As posições da escola bancária só prevaleciam em períodos excepcionais, notadamente em momentos de crise como 1825, 1836, 1839 e $1847 .{ }^{9}$

\section{0 debate inglês "tropicalizado"}

Dada a semelhança das discussões inglesa e brasileira, Saes conclui que o pensamento monetário europeu chegava ao Brasil, "mas já era processado de modo a refletir os problemas particulares da economia brasileira". ${ }^{10} 0$ debate inglês era, por assim dizer, "tropicalizado" e traduzia-se por aqui na controvérsia entre papelistas, defensores do princípio bancário, e metalistas, que sustentavam o princípio monetário. Na verdade, não havia na Assembleia Legislativa brasileira dois grupos uniformes e bem definidos representando papelistas e metalistas $e_{1}$ a julgar pelos discursos proferidos à época no parlamento, nem os próprios debatedores se identificavam dessa maneira. Esses adjetivos foram incorporados posteriormente por conta da historiografia sobre 0 assunto. ${ }^{11}$ Contudo, apesar de certa arbitrariedade, eles são úteis para que nos situemos melhor no debate.

Discutiam-se no Brasil as mesmas questões tratadas no debate inglês, isto é, direito de emissão e conversibilidade do meio circulante. 0 posicionamento dos dois grupos em relação a essas questões é análogo ao das escolas inglesas. 0 giro dos negócios era a preocupação principal dos papelistas, assim, reclamavam que a quantidade de moeda em circulação deveria ser suficiente para garantir a efetivação das transações. Para que isso ocorresse, admitiam um meio circulante lastreado ou não em metais. Pensavam nessa alternativa justamente por causa da escassez de metais que costumava grassar na economia brasileira. Seria possivel paralisar as transações por conta da insuficiência de moeda decorrente de tal escassez? Para um papelista, admitir essa possibilidade seria absurdo. 0 elemento determinante da oferta monetária deveria ser a demanda por moeda para transações. Se o aumento da oferta monetária acompanhasse pari passu o aumento do volume de transações, não haveria motivo para que a moeda brasileira se desvalorizasse.

Aparentemente, tais preocupações revelavam os interesses de frações da classe dominante ligadas mais ao setor interno do que ao setor externo da economia. Daí a preocupação secundária com a estabilidade do câmbio, resultante, para os papelistas, do movimento da balança comercial. De fato, numa economia mercantil e escravista como a brasileira, o câmbio estava 
FURTADO, Celso. Formação econômica do Brasil. São Paulo: Cia das Letras, 2007. sempre sujeito à instabilidade porque seu valor dependia dos preços e das condições de demanda por produtos nativos no mercado externo, como bem apontou Furtado. ${ }^{12}$

Então, de acordo com o princípio bancário, era o volume de transações que determinava a quantidade de emissão de notas bancárias. Se a cada emissão correspondesse uma transação, o problema do excesso de emissão simplesmente não existiria. Caso existisse, o excesso de demanda por notas bancárias faria subir a taxa de juros e a emissão se ajustaria a ela. A taxa de juros seria, portanto, a variável de ajuste da oferta de notas bancárias. Livres do problema do excesso de emissão, os papelistas apontavam a pluralidade emissora por meio de bancos privados como a melhor maneira de atender à demanda por moeda das praças e garantir o giro dos negócios. Além disso, a pluralidade asseguraria melhor distribuição do meio circulante entre as praças.

De olho no setor externo da economia, os metalistas sustentavam que a quantidade de moeda em circulação deveria ser tal que mantivesse o seu valor estável, pois a estabilidade da taxa de câmbio era sua preocupação principal. Em princípio, não havia concessão quanto à conversibilidade. 0 meio circulante deveria ser metálico ou totalmente lastreado em metal. Nesse caso, a oferta de metal deveria ser proporcional ao volume de transações para que houvesse moeda suficiente para efetivá-las. Mas isso era uma quimera, sobretudo no contexto brasileiro, em que a escassez de metal era a regra.

Seguindo à risca o sistema de conversibilidade total, a escassez de metal implicaria a insuficiência de moeda e poderia paralisar as transações. A questão que então se apresentava era: paralisar as transações ou manter o lastro metálico da moeda? Teoricamente, um metalista ficaria com a primeira opção. Contudo, na prática, os metalistas do Império arranjavam uma alternativa para manter o giro dos negócios, mesmo que isso pudesse comprometer o valor da moeda. 0 segundo Banco do Brasil andará o tempo todo na corda bamba entre o giro do comércio e o lastro de suas notas.

De fato, o que devia determinar a oferta de moeda era a política econômica definida pelo governo. No caso de uma política metalista, qualquer movimento de desvalorização da moeda indicaria emissão de moeda mais do que suficiente para garantir a realização das transações e requereria a intervenção do governo para enxugar o excesso de moeda em circulação. No entanto, as consequências dessa intervenção para o comércio eram frequentemente consideradas nas decisões governamentais.

Aparentemente, a preocupação com o câmbio revelava os interesses de frações da classe dominante ligadas ao setor externo da economia. Daí a preocupação secundária com a taxa de juros, resultante, para os metalistas, da interação da oferta e demanda por moeda. As notas bancárias não afetariam a taxa de juros por serem meros instrumentos de crédito e não moeda propriamente.

Então, de acordo com o princípio monetário, a oferta de moeda estava ligada à inflação e, conseqüentemente, ao câmbio. Como a taxa de câmbio seria determinada pela quantidade de moeda em circulação, era ela a variável que sinalizaria a necessidade de se ajustar ou não a oferta de moeda. Se aquela quantidade fosse maior do que o volume de transações, a taxa de câmbio se desvalorizaria e sinalizaria excesso de emissão, exigindo que o governo lançasse mão da política econômica para enxugar o excesso de moeda. A taxa de câmbio seria, portanto, a variável de ajuste da oferta de moeda. 
Cf. as posições a respeito da conversibilidade defendidas por Torres Homem, tido como metalista, e Souza Franco, tido como papelista, respectivamente, em BRASIL. MINISTÉRIO DA FAZENDA. Proposta e relatorio apresentados á Assembléa Geral Legislativa na Terceira Sessão da Décima Legislatura do anno de 1858 pelo Ministro e Secretario d'Estado dos Negocios da Fazenda Francisco de Salles Torres Homem. Rio de Janeiro: Typ. Nacional, 1859. p.2 e FRANCO, Bernardo de Souza. Os bancos do Brasil:sua história, defeitos da organização atual e reforma do sistema bancário. Brasília: Editora Universidade de Brasília, 1984. p.87. VILLELA, André Arruda. Op. Cit., p.275 distingue ainda, dentro do grupo papelistas, o comum (ordinary), como Souza Franco, que defende a conversibilidade, e o verdadeiro (true), como Mauá, que preferem a moeda fiduciária.

14

As regras de criação e operação dos bancos estavam inseridas em legislações mais amplas, como a lei das sociedades anônimas, de 1849 , e 0 código comercial, de 1850.

15

TEIXEIRA, Arilda Magna Campanharo. 0p. Cit.

16

Nasceu em Mariana, Minas Gerais, em 1805. Ligado ao jornalismo, fundou o Patriota Mineiro e foi um dos chefes da revolução liberal (1842). Foi deputado por Minas Gerais e ministro da fazenda. Foi ainda presidente e diretor do Banco do Brasil. Faleceu em 1881. Cf. CARM0, José de Arimatéia Pinto do. Ministros da Fazenda. Rio de Janeiro: Pongetti, 1944.

17

Nasceu no Rio de Janeiro, em 1830. Bacharel em Ciências Jurídicas e Sociais pela Academia de São Paulo. Foi deputado (1869) e senador (1873) pelo Rio de Janeiro. Foi também ministro da agricultura, comércio e obras públicas (1870). Nomeado para o conselho de Estado em 1874, faleceu em Roma, em 1892. Cf. VASCONCELLOS, barão; SMITH DE VASCONCELLOS, barão. Archivo nobiliarchico brasileiro. Lausanne: Imprimerie La Concorde, 1918. p.139-140.
Para finalizar essa caracterização geral de papelistas e metalistas, é preciso lembrar que, assim como as escolas bancária e monetária, ambos os grupos concordavam que a moeda devia ser conversivel e, se possivel, que a conversão fosse feita em metal. A diferença é que os papelistas aceitavam uma relação mais fraca entre a moeda e o metal, admitindo o lastro em títulos da dívida pública quando houvesse escassez de metal. ${ }^{13}$

0 debate "tropicalizado" também dizia respeito ao direito de emissão e ao tipo de conversibilidade do meio circulante. Quanto ao direito de emissão, discutia-se sua unidade ou pluralidade, questão que também remetia à nacionalização ou provincialização da circulação das notas emitidas. Entre 1808 e 1836, prevaleceu no Brasil a unidade de emissão, primeiro com o Banco do Brasil, depois com o tesouro. A questão da pluralidade só reapareceu mais fortemente com os bancos emissores de vales fundados em várias províncias a partir de 1836, no vácuo de uma legislação específica sobre a criação e operação de bancos. ${ }^{14}$ Entre o final da década de 1830 e 1853, 0 Brasil viveu, de fato, uma experiência de pluralidade de emissão supervisionada pelo governo bem ao gosto papelista, embora nessa época tivessem passado pelo governo ministros da fazenda mais alinhados ao grupo metalista, como Rodrigues Torres. Tal fato indica a dificuldade de enquadramento dos atores políticos nos dois grupos a que estamos nos referindo.

Caracterizados papelistas e metalistas e as controvérsias em que estavam metidos, é preciso tentar identificar quem é quem no debate travado na Assembleia Legislativa brasileira. Já advertimos que seria temerário considerar papelistas e metalistas como grupos homogêneos e bem definidos. Mesmo que houvesse papelistas e metalistas puros nas idéias, na prática, suas ações eram uma mescla das duas posições, conforme sugerem as gestões de Souza Franco e Torres Homem no Ministério da Fazenda. Contudo, é possivel indicar a orientação geral de alguns parlamentares em relação à questão financeira por meio de seus posicionamentos nos debates parlamentares.

Com base no estudo de Arilda Teixeira ${ }^{15}$ sobre a política monetária brasileira no Segundo Império, situamos a seguir a inclinação teórica em assuntos financeiros de atores que mais tarde influenciarão as atividades do segundo Banco do Brasil. De tendência papelista temos Irineu Evangelista de Souza, futuro diretor e membro da comissão fiscal; Francisco de Paula Santos, futuro diretor; e José Pedro Dias de Carvalho, ${ }^{16}$ futuro diretor e vice-presidente do banco. De tendência metalista temos Rodrigues Torres, futuro membro da comissão fiscal e presidente; Silva Ferraz, futuro membro da comissão fiscal e suplente de diretor; Torres Homem, futuro presidente; Jerônimo José Teixeira Júnior, futuro visconde de Cruzeiro ${ }^{17} \mathrm{e}$ futuro diretor; e José Machado Coelho de Castro, futuro diretor do banco. Rodrigues Torres, Torres Homem, Silva Ferraz e Dias de Carvalho também foram ministros da fazenda, o que indica que a estreita relação entre Estado e banco não se dava apenas na nomeação, por parte do imperador, de presidente e vice-presidente da instituição, mas também no acompanhamento de suas operações cotidianas. Os homens do banco muitas vezes eram também homens do governo.

Aliás, o debate entre papelistas e metalistas remete ao processo político de construção do Estado imperial, uma vez que a administração da moeda é um de seus alicerces fundamentais. 0 que acabamos de discutir nada mais é do que o embate entre modos alternativos de administrar a moeda do país que implicariam a redistribuição do poder político entre Corte e províncias, pois a outra face da discussão sobre pluralidade ou 
LEVY, Maria Bárbara; ANDRADE, Ana Maria Ribeiro de. Fundamentos do sistema bancário no Brasil: 1834-1860. Estudos Econômicos, São Paulo, v.15, número especial, p.17-48, 1985. p.19.

19

GUIMARÃES, Carlos Gabriel. Bancos, Economia e Poder no Segundo Reinado: o caso da sociedade bancária Mauá, Macgregor \& Companhia (1854-1866). 1997. 306f. Tese (Doutorado em História Econômica). Faculdade de Filosofia, Letras e Ciências Humanas, Universidade de São Paulo, 1997.

20

SESSÃO de 8 de março de 1850. Câmara dos Deputados. Brasil. Anais da Câmara dos Deputados, p.93. Disponível em: $<$ http://imagem.camara.gov.br/dc_20b. asp?selCodColecaoCsv=ACtDatain=8/3/1850>. Acesso em: 01 fev. 2014. unidade de emissão é a descentralização ou centralização do poder político. ${ }^{18} 0$ duelo entre os dois grupos podia ser traduzido imediatamente no conflito entre Corte e províncias. No entanto, embora a relação entre poder descentralizado e papelismo seja estreita, não é possivel associar sem mais frações das classes dominantes provinciais às idéias papelistas. A unidade de emissão, isto é, a centralização do poder na Corte, era defendida por grupos ligados ao comércio externo e por proprietários de terra escravistas não só do centro-sul como também das províncias do norte. A pluralidade de emissão era sustentada por grupos mais ligados ao comércio interno, que sentiam mais a escassez de moeda para efetivar suas transações ${ }^{19}$.

0 debate econômico guiava ações políticas. No início da década de 1850, Holanda Cavalcanti apresentou um projeto que previa a criação de bancos de emissão nas províncias, ratificando a pluralidade existente. Nesse quadro, Rodrigues Torres, então ministro da fazenda, propôs um contra-projeto que previa a criação de um banco privado, mas sob influência estatal, com monopólio de emissão de notas. 0 ministro, de olho na estabilidade do valor da moeda e do câmbio, preocupava-se com a possibilidade de excesso de emissão trazida pela pluralidade e que já se manifestava na crise monetária de 1853 envolvendo a competição entre o Banco Comercial do Rio de Janeiro e o Banco do Brasil, de Irineu Evangelista de Souza, os dois bancos emissores da praça do Rio.

Essa crise certamente contribuiu para que a proposta de Rodrigues Torres, de cunho metalista, prevalecesse sobre a proposta de Holanda Cavalcanti, de cunho papelista. Desse embate nasceria o segundo Banco do Brasil com o monopólio da emissão de notas bancárias. A pluralidade de emissão só voltaria em 1857, com a chegada de Souza Franco ao Ministério da Fazenda, dentro do espírito político da chamada conciliação. Contudo, foi uma curta experiência que terminaria com a contraofensiva de seus sucessores, respectivamente, Francisco de Salles Torres Homem e Ângelo Muniz da Silva Ferraz. É verdade que a lei de 1860, chamada lei dos entraves, não previa formalmente a unidade de emissão, mas impôs condições tão restritivas para que se pudesse emitir que, na prática, o Banco do Brasil voltaria a ser o único banco emissor do Império. A unidade de emissão só seria restabelecida formalmente em 1866, quando houve a revisão dos estatutos do Banco do Brasil, desta vez como monopólio do tesouro.

Já dissemos que papelistas e metalistas concordavam com a conversibilidade da moeda. A discordância nesse âmbito dizia respeito ao tipo de conversibilidade. As posições de Souza Franco e Rodrigues Torres quanto à matéria ilustram a controvérsia. Enquanto reconhecia que a moeda metálica era preferivel a qualquer outra do ponto de vista exclusivo da segurança da moeda, Souza Franco também criticava que ela dificultava a sustentação de instituições de crédito, indispensáveis ao comércio, e chamava atenção para o alto custo de oportunidade envolvido no emprego de metais para produzir moeda. Para contornar esses percalços, defendia um meio circulante lastreado apenas parcialmente em metais, o que era inconcebível para seu antípoda, defensor da solidez da moeda e da segurança que ela traria aos negócios. Citando David Ricardo, Rodrigues Torres enfatizava a importância do papel moeda realizável para "a tranqüilidade e segurança dos negócios de comércio".20

Seguindo essa linha, o governo brasileiro invariavelmente tentou garantir a conversibilidade de suas notas em metal. Na maioria das vezes sem sucesso, como mostraram as experiências do primeiro Banco do Brasil 
21

Essa discussão ocorreu nas sessões de 7 e 8 de março e 25 e 26 de abril de 1850. Depois de longos debates, a provincialização do meio circulante defendida por Rodrigues Torres e criticada por Souza Franco acabou aprovada como lei 552, de 31 de maio de 1850. No entanto, a provincialização não chegou a ser levada a cabo pelo governo. Importante lembrar que 0 art. $3^{\circ}$ dessa lei proibia o aumento da "soma de papel circulante no império". Cf. BRASIL. MINISTÉRIO DA FAZENDA. Proposta e relatorio apresentados a Assembléa Geral Legislativa na Terceira Sessão da Oitava Legislatura do anno de 1850 pelo Ministro e Secretario d'Estado dos Negocios da Fazenda Joaquim José Rodrigues Torres. Rio de Janeiro: Typ. Nacional, 1851. p.35. e da reforma de 1833, embora esta última tenha contribuído para melhorar o estado do meio circulante no início do período regencial. A reforma de 1846 quebrou novamente o padrão monetário e estabeleceu uma nova paridade do mil-réis em relação à moeda inglesa, a fim de tornar o meio circulante brasileiro conversível em ouro e assim garantir a estabilidade dos preços e do câmbio. Porém, a manutenção da paridade e a conversibilidade só viriam com a criação do segundo Banco do Brasil, mesmo assim em breves períodos entre 1854 e 1864. Além disso, não se pode esquecer que, no Império, as ideias metalistas tinham que ceder à realidade de uma economia mercantil e escravista, de modo que a conversão das notas do banco poderia ser feita em metal ou em notas do tesouro. Como estas últimas não eram conversíveis em metal, o meio circulante era apenas parcialmente conversivel em ouro.

\section{0 segundo Banco do Brasil no debate parlamentar}

Quanto aos bancos especificamente, o grupo papelista defendia a pluralidade de instituições emissoras privadas não só por uma questão de liberdade - o livre mercado e a livre iniciativa deviam vigorar apesar da escravidão -, como por uma questão de geografia, isto é, a dificuldade de capilarização das notas de um banco emissor centralizado num ponto específico do vasto território brasileiro. Somente a pluralidade seria suficiente para garantir o giro dos negócios e a efetivação das transações tanto na Corte como nas províncias. Eram os homens do crédito.

Já o grupo metalista, que pretendia sustentar a paridade fixada em 1846, defendia a criação de uma única instituição emissora sob a tutela do Estado, que se encarregaria de regular o volume de emissões de acordo com a necessidade da economia. A provisão de liquidez ao mercado ficaria subordinada à manutenção do valor da moeda. Teoricamente, eram os homens da moeda. Mas só teoricamente, pois a realidade econômica brasileira não cedia espaço para o idealismo metalista.

Para mostrar como os bancos apareciam no debate, sobretudo possiveis referências que aparecerão mais tarde na criação do segundo Banco do Brasil, selecionamos falas dos dois políticos que talvez tenham sido os mais influentes em assuntos financeiros e bancários em sua época: Souza Franco e Rodrigues Torres. Essas falas tiveram lugar nas sessões da Câmara em que se deu a extensa discussão sobre a provincialização do meio circulante ${ }^{21}$ e em trabalhos impressos dos dois contendores, a saber, o opúsculo Os bancos do Brasil, do primeiro, e os relatórios do Ministério da Fazenda, do segundo.

De maneira geral, Souza Franco e Rodrigues Torres atrelavam a reforma monetária à reforma do sistema bancário, mas havia discordância quanto ao momento de se criar um banco ou bancos de emissão para auxiliar o governo no controle da oferta de crédito e moeda. Nesta ordem, para Souza Franco, e na ordem inversa, para Rodrigues Torres. Para o deputado paraense, o governo devia criar imediatamente, isto é, por volta de 1850, época em que ocorreu a discussão sobre essa matéria, um banco de emissão para que fosse garantido o crédito necessário ao comércio e, ao mesmo tempo, para que fosse valorizado o meio circulante por meio da substituição das notas do tesouro por notas do banco.

$\mathrm{Na}$ apreciação do projeto de provincialização do meio circulante proposto na Câmara pelo então ministro da fazenda Rodrigues Torres, a questão dos bancos aparecia freqüentemente. Na sessão do dia 8 de março, 
SESSÃO de 25 de abril de 1850. Câmara dos Deputados. Brasil. Anais da Câmara dos Deputados, p.481. Disponivel em: $<$ http://imagem.camara.gov.br/dc_20b. asp?selCodColecaoCsv=A\&tDatain $=25 / 4 / 1850>$. Acesso em: 01 fev. 2014.

Cf. GAMBI, Thiago Fontelas Rosado. Considerações sobre a primeira fusão de bancos no Brasil. Leituras de economia política, Campinas, n.13, p.99-123, 2008; VILLELA, André Arruda. Op. Cit.; FRANCO, Afonso Arinos de Melo; PACHECO, Cláudio. História do Banco do Brasil. Brasília: Banco do Brasil, 1979.
Souza Franco criticou o ministro, que estava presente à sessão, por sua restrição à criação de bancos emissores. Além de referir-se ao caso bem sucedido do Banco da Bahia, fundado em 1845, utilizou os exemplos europeus da Inglaterra, Irlanda e Escócia em sua crítica. ${ }^{22}$

Como já havia proposto anteriormente, inclusive em seu projeto de reforma bancária de 1848, o deputado voltou à carga na sessão de 25 de abril defendendo a criação imediata de bancos de emissão, mesmo que lastreada em títulos públicos. Não seria preciso esperar a redução do papelmoeda em circulação nem uma composição ideal do estoque de moeda, entre metal e papel, para que tais bancos fossem criados, como mostravam os exemplos da Inglaterra e dos Estados Unidos. ${ }^{23}$

Como já dissemos, a política econômica de Rodrigues Torres visava estabilizar o valor do mil-réis e, em sua perspectiva, para que isso ocorresse seria preciso enxugar o meio circulante, isto é, reduzir o volume de papelmoeda em circulação, seguindo nesse aspecto a teoria quantitativa da moeda. Para ele, ainda não era o momento de se criar bancos de emissão no Brasil, pois tais bancos poderiam elevar o volume de papel-moeda em circulação e levar à desvalorização da moeda, mas reconhecia sua importância para o comércio e a indústria como ofertantes de crédito.

Vale notar que o problema do ministro era com bancos de emissão e não com bancos de depósitos e descontos, pois em sua concepção estes não criavam moeda. Aliás, os metalistas de maneira geral não viam os bancos de depósitos e descontos como criadores de moeda, o que se pode comprovar com a autorização dada pelo ministro Torres Homem, em 1859, para a criação de vários desses bancos num momento em que era claro o objetivo de redução do volume do meio circulante. Na sessão do dia 8 de março já referida, em resposta a Souza Franco, Rodrigues Torres dizia não duvidar de que

até certo ponto os bancos facilitem [sic] o movimento das operações comerciais; mas se as facilitam por um lado, muitas vezes prejudicam-nas consideravelmente, dando-Ihes excitamento perigoso, fazendo que se empreendam operações, quer de indústria, quer de comércio, que não têm nenhuma probabilidade de ser bem sucedidas. Não quero dizer com isso que sou inimigo de bancos, torno a repetir que não; mas nas circunstâncias em que se acha o país, quando a nossa circulação é papel-moeda, não posso ser partidista dos bancos de emissão, porque a única vantagem que eu acho nestes estabelecimentos, a única coisa para que eles prestam, que não pode ser satisfeita pelos bancos de descontos, é substituir parte de um instrumento custoso de circulação por outro muito menos dispendioso; mas se o nosso instrumento de circulação não é metálico, não é dispendioso, que benefício nos pode vir dos bancos de emissão? (...) Para que pois bancos de emissão? Virá época em que eles serão úteis: preparemos o terreno; tenhamos uma circulação mais sólida, já em parte garantida por moeda metálica, já pelo maior crédito que resultará ao papel pela retirada de uma porção dele, então poderá ser judiciosa, útil a organização de um ou mais bancos, mas bancos organizados para substituir o papelmoeda do governo por notas suas, não me parecem convenientes, porque o papel dos bancos converter-se-á brevemente em papel-moeda [grifo nosso]. ${ }^{24}$

Quem lesse apenas essas palavras do ministro não poderia imaginar que três anos depois ele seria o mentor da criação de um banco emissor justamente para substituir o papel-moeda do governo por suas notas. No entanto, não se tratava de uma mudança de posição em relação ao assunto, como apontou Gambi, nem mesmo de uma mudança parcial, como apontou Villela. Como bem observa Pacheco, embora criticasse os bancos de emissão àquela altura, Rodrigues Torres deixara uma porta aberta para a criação de tais bancos ao atrelá-la à conjuntura ${ }^{25}$. 

dos Deputados. Brasil. Anais da Câmara dos Deputados, p.498. Disponível em: $<$ http://imagem.camara.gov.br/dc_20b. asp?selCodColecaoCsv=ActDatain=26/4/1850 > . Acesso em: 01 fev. 2014

28

BRASIL. MINISTÉRIO DA FAZENDA. Proposta e relatorio apresentados á Assembléa Geral Legislativa na Primeira Sessão da Oitava Legislatura do anno de 1849 pelo Ministro e Secretario d'Estado dos Negocios da Fazenda Joaquim José Rodrigues Torres. Rio de Janeiro: Typ. Nacional, 1850. p.36.
É fato que ele não concordava com a criação imediata de bancos de emissão, mas vislumbrava um momento em que ela poderia se tornar útil para o pais e tal momento chegaria quando a emissão dos bancos pudesse ser lastreada em metais. Todo o problema do ministro aqui era o medo de que as notas dos bancos emissores entrassem em circulação como papel-moeda, o que de fato acontecia, e contribuíssem para desvalorizar o mil-réis. Em sua visão, ao promover a desvalorização da moeda, a concorrência entre notas de bancos e notas do governo seria prejudicial para a economia do país.

0 que fará então o ministro em 1853? Chegado o momento, por meio da criação de um banco com monopólio de emissão, promoverá justamente a troca das notas do tesouro por notas do novo banco, ou seja, depois de algum tempo, teoricamente, o meio circulante nacional deveria ser composto exclusivamente por notas do segundo Banco do Brasil conversiveis em metal. Na nova instituição, permaneceriam a unidade de emissão e o ideal do lastro metálico, conforme sempre defendeu. Naquela altura, a conjuntura mudara, daí o momento de se criar um banco para auxiliar o governo na manutenção do valor da moeda, mas as idéias de Rodrigues Torres permaneceram as mesmas.

Voltando à questão dos bancos no debate entre papelistas e metalistas, neste caso, especificamente no debate entre o deputado Souza Franco e o ministro Rodrigues Torres, este último também rebateu a indicação de experiências estrangeiras como modelos para o Brasil. ${ }^{26} \mathrm{Na}$ concepção do ministro, não era possivel transplantar os casos da Europa e da América do Norte para o Brasil sem mais, pois a quantidade de moeda em circulação dependia das condições da economia de cada país.

Na sessão de 8 de março, num discurso alinhado ao da escola monetária, o ministro advertia Souza Franco que não se podia confundir meio circulante e capital. Para ele, o volume de negócios de um país não dependia do volume do meio circulante, mas da quantidade de capital utilizada na produção. Sendo assim, um aumento da quantidade de moeda em circulação não faria aumentar os capitais e tampouco os negócios. Então, para que emitir notas bancárias?

Apesar de não se dizer contrário aos bancos, Rodrigues Torres mostrava pelo menos certa desconfiança quanto à sua atuação ao descrever o processo que levava uma instituição desse tipo do boom ao crash. Interessante notar como as crises financeiras, com a introdução de inovações financeiras, foram se tornando mais complexas ao longo do tempo, mas mantiveram uma fonte comum, a saber, a relação real básica entre os primeiros credores e devedores. Mas seu ponto era mesmo a valorização da moeda. Em seu discurso nada havia contra os bancos em si, mas tudo contra o momento de criá-los, conforme suas palavras nas sessões da Câmara dos deputados de 25 e 26 de abril de $1850 .{ }^{27}$ Era a mesma posição já antes expressa na famosa passagem do relatório do Ministério da Fazenda de 1849 em que sintetizou sua posição a respeito dos bancos e da utilização de um banco para auxiliar o governo no resgate do papel-moeda.

\footnotetext{
Não sou avesso às instituições bancais: reconheço os grandes serviços que podem prestar ao Brasil: faço mesmo votos para que se criem em todas as nossas províncias bancos de depósitos e descontos, que reúnam as economias e capitais dormentes, e os emprestem sob condições vantajosas a quem possa empregá-los utilmente: concorreram assim para fecundar a indústria e enriquecer o país; mas não concebo por ora que utilidade poderiam ter os bancos de emissão, nem como é possivel combinar a existência deles com a diminuição da massa do papel circulante, como é indispensável para fixar-lhe o valor. ${ }^{28}$
} 
29

SESSÃO de 8 de março de 1850. Op. Cit., p.99. e relatorio apresentados á Assembléa Geral Legislativa na Primeira Sessão da Oitava Legislatura do anno de 1849..., Op.Cit., p.35. 32 SESSÃO de 25 de abril de 1850. Op. Cit., p.485.

Além de apontar o embaraço que os bancos emissores poderiam causar à estabilidade do valor do meio circulante, Rodrigues Torres também chamou a atenção para o fato de não haver no Império condições mínimas para a organização desses bancos levada a cabo pela iniciativa privada. Segundo ele, talvez ao se lembrar de 1833, para que os bancos se organizassem era preciso capital e vontade por parte dos capitalistas, o que ainda não havia no país. ${ }^{29}$

Essa posição de Rodrigues Torres, expressa num discurso pronunciado na Câmara em março de 1850, causa bastante estranheza. É certo que a abolição do tráfico, que liberaria os capitais reclamados pelo ministro para serem aplicados em outras atividades, inclusive no setor bancário, só viria em setembro, mas a década de 1840 assistiu ao surgimento de bancos comerciais em várias províncias. Vontade não parecia faltar aos possuidores de fundos. Mas é preciso lembrar que os discursos são muitas vezes produzidos por atores envolvidos na questão e que podem, eventualmente, manipular a informação de acordo com seus interesses. Por isso, antes de partir para a análise do que foi registrado, é necessário saber quem fez o discurso, com que finalidade tal discurso foi produzido e a que público se destinava, de modo que não é possivel desatrelar esse trecho do discurso feito para deputados pelo ministro da fazenda Rodrigues Torres de sua posição mais ampla a respeito dos bancos. A realidade era aparentemente sacrificada em nome de suas convicções. Souza Franco foi direto ao ponto quando disse que

\section{(...) todo o receio do Sr. ministro a respeito dos bancos não é porque quebrem ou porque não vivifiquem a indústria, mas sim que o seu papel venha a embaraçar o papel do governo: eis aqui toda a questão. Para se não depreciar o papel do governo, esmoreça embora o crédito por toda parte, não reúnam os capitais mortos, dispersos, desempregados, nem venham favorecer a indústria! [grifo nosso] ${ }^{30}$}

De fato, o ministro considerava a estabilidade do valor da moeda e do câmbio pré-condição para o aumento da riqueza do país. Em seu relatório de 1849, ele apontou os inconvenientes da instabilidade do valor da moeda e do câmbio e defendeu que o governo lançasse mão de todos os recursos disponíveis para estabilizar tais valores, $\mathrm{e}$, se o momento fosse $\mathrm{o}$ adequado, inclusive criar um banco que pudesse controlar a oferta de moeda em todo o Império. A manutenção da paridade definida pela lei de 1846, considerada por Rodrigues Torres um dos atos mais sensatos do legislativo brasileiro, seria um compromisso solene entre o Estado e o país, sendo, pois, peremptória sua defesa. ${ }^{31}$

No ano seguinte, Rodrigues Torres demonstrava na Câmara sua preocupação com a depreciação do câmbio. Em seu diagnóstico, a instabilidade cambial indicava que o país não tinha um "sistema financeiro fundado sobre bases sérias" ${ }^{\prime 2}$ e isso impedia o desenvolvimento da indústria e do comércio. Como vimos, a essa altura ele ainda não propunha a criação de um banco de emissão para auxiliar o governo a resolver esse problema, pois, a seu ver, a conjuntura para tal não estava dada.

A posição de Souza Franco contrastava claramente com a de Rodrigues Torres, mas sua proposta de criação de bancos emissores não vinha desacompanhada do papel que caberia ao Estado em seu arranjo bancário, como mostra esta passagem de seu livro já referido:

Considerada a interferência dos governos nos bancos no ponto de vista social e financeiro e sem interesse de partido é uma necessidade da sociedade, e de grande 
33

FRANCO, Bernardo de Souza. Op. Cit., p.85.

34

SESSÃO de 25 de abril de 1850. Op. Cit., p.481-482. vantagem pelos abusos que pode coibir. Nos governos representativos é até sem perigo porque como violentar os interesses dos acionistas e diretores dos bancos? Então há muito mais a recear dos desvios a que o engodo de ganhos excessivos arraste o banco e suas direções. E privar o governo da influência precisa sobre os bancos seria mais um exemplo da inqualificável anomalia de em um Estado em que estão sujeitos à ação governativa todos os atos públicos, excetuar instituições de tão grande importância, e de cujos abusos resultam sérios embaraços à administração pública. E quando aliás pode dar-se a influência dos Poderes do Estado sem que daí venha ao Tesouro direito para impor sua vontade nos contratos com os bancos que parece ser o ponto da questão e dos receios da influência governativa [grifos nossos] ${ }^{33}$.

As palavras acima sugerem que os bancos deviam ser regulados pelo Estado, e não por partidos, vale ressaltar, para que não houvesse o risco de cometerem os abusos motivados pela ilusão de grandes lucros. Além disso, na sessão da Câmara de 25 de abril, Souza Franco dizia que quando um banco particular estivesse ligado aos interesses do Estado, como na questão do meio circulante, o governo deveria dar garantias e privilégios a essa instituição. ${ }^{34} \mathrm{Na}$ proposta de Rodrigues Torres que logo se apresentaria, o banco sugerido não seria oficial, mas deveria ficar sob a tutela do Estado, que Ihe ofereceria garantias e seria responsável pela nomeação do presidente e do vice-presidente do banco. Ele, inclusive, seria nomeado presidente da instituição.

As ideias relativas à criação de um banco ou bancos de emissão, que já vinham sendo apresentadas desde a liquidação do primeiro Banco do Brasil, foram fermentando no final da década de 1840 e início de 1850. Na sessão de 26 de abril daquele ano, o discurso do deputado Francisco de Paula Sousa e Melo indicava o caminho do monopólio de emissão e de saneamento do meio circulante que seria seguido pelo governo imperial dentro de pouco tempo:

Quisera porém que este banco[de emissão] fosse criado com a condição de poder elevar anualmente o seu fundo capital, e as suas emissões na razão das somas de papel que o governo retirasse da circulação, de sorte que caminhando o banco por um lado no aumento de suas emissões, e o governo por outro lado no consumo e queima do papel, no fim de certo número de anos a soma atualmente em circulação estivesse preenchida por papel do banco. Penso que este banco assim instituído não correria tantos perigos, e nem com ele a moeda do governo ficaria exposta a depreciações [grifo nosso]. ${ }^{35}$

Ao apresentar sua ideia de criar um banco de emissão e de como ele poderia auxiliar o governo a fortalecer o meio circulante, o deputado pela província de São Paulo foi quem mais se aproximou do que viria a ser o segundo Banco do Brasil, criado em 1853.

\section{Considerações finais}

0 debate entre papelistas e metalistas revela a disputa de duas posições distintas em relação ao monopólio de emissão e, por extensão, à centralização do poder político no Império brasileiro. No contexto desse debate, o governo imperial, conduzido pelo Partido Conservador, seguirá predominantemente uma política econômica de cunho metalista nas décadas de 1850 e 1860 .

Em 1852, Rodrigues Torres apresentou o projeto de criação de um banco emissor que previa a substituição das notas do tesouro por notas desse banco conversiveis em ouro. Outros elementos presentes na discussão sobre o meio circulante, como a criação de um banco de resgate de notas do tesouro e a tomada por parte do governo de um empréstimo junto 
Cf. PELÁEZ, Carlos Manuel; SUZIGAN, Wilson. História monetária do Brasil. Análise da política do comportamento e das instituições monetárias. Brasília: UNB, 1981. p.76; para os "Meios de proteger a indústria", cf. BRASIL. MINISTÉRIO DA FAZENDA. Proposta e relatorio apresentados á Assembléa Geral Legislativa na Primeira Sessão da Oitava Legislatura do anno de 1849..., Op. Cit., p.32-35. ao banco criado para tal fim, serão notados no projeto de Rodrigues Torres. Por isso, o debate entre papelistas e metalistas sobre a questão bancária fez parte do processo de gestação do que viria a ser o segundo Banco do Brasil e influenciou decisivamente os rumos da política econômica imperial em meados do século XIX. Ainda que considerado um eclético, ${ }^{36}$ as posições de Rodrigues Torres marcaram a política econômica levada a cabo pelo Ministério da Fazenda entre 1848 e 1853, e continuaram a influenciá-la nos anos seguintes.

0 fio condutor dessa política seria a estabilização do valor da moeda, com vistas à obtenção de uma moeda forte, condição para a montagem de uma economia civilizada, no contexto de um projeto político levado a cabo pelo Partido Conservador. A administração centralizada da oferta de moeda e o monopólio de sua emissão concretizados no segundo Banco do Brasil consistiriam, por assim dizer, o braço financeiro desse projeto. Além disso, a sustentação de uma moeda forte casava-se, de maneira mais específica, com os compromissos externos assumidos pelo governo imperial, inclusive via construção de confiança nos credores estrangeiros e, de maneira mais geral, com os planos civilizatórios desse grupo político.

Economia e política, banco e Estado, estavam imbricados nas discussões entre papelistas e metalistas, inclusive quanto à recriação de uma grande instituição financeira que pudesse auxiliar no saneamento do meio circulante do Império e no fornecimento de crédito à praça. Não se tratava apenas de criar um segundo Banco do Brasil, tratava-se de criar um banco atrelado a um projeto político que impunha uma direção ao governo do Império brasileiro. 